\title{
Confocal Imaging of Pseudomonas syringae pv. phaseolicola Colony Development in Bean Reveals Reduced Multiplication of Strains Containing the Genomic Island PPHGI-1
}

\author{
S. A. C. Godfrey, ${ }^{1}$ J. W. Mansfield, ${ }^{2}$ D. S. Corry, ${ }^{1}$ H. C. Lovell, ${ }^{1}$ R. W. Jackson, ${ }^{3}$ and D. L. Arnold ${ }^{1}$ \\ ${ }^{1}$ Centre for Research in Plant Science, The University of the West of England, Bristol, BS16 1QY, U.K.; ${ }^{2}$ Division of Biology, \\ Imperial College London, London, SW7 2AZ, U.K.; ${ }^{3}$ School of Biological Sciences, University of Reading, RG6 6AJ, U.K.
}

Submitted 18 May 2010. Accepted 27 June 2010.

\begin{abstract}
Pseudomonas syringae pv. phaseolicola is the seed borne causative agent of halo blight in the common bean Phaseolus vulgaris. Pseudomonas syringae pv. phaseolicola race 4 strain 1302A contains the avirulence gene hopARI (located on a 106-kb genomic island, PPHGI-1, and earlier named avrPphB), which matches resistance gene $R 3$ in $P$. vulgaris cultivar Tendergreen (TG) and causes a rapid hypersensitive reaction (HR). Here, we have fluorescently labeled selected Pseudomonas syringae pv. phaseolicola $1302 \mathrm{~A}$ and 1448A strains (with and without PPHGI-1) to enable confocal imaging of in-planta colony formation within the apoplast of resistant (TG) and susceptible (Canadian Wonder $[\mathrm{CW}]) \boldsymbol{P}$. vulgaris leaves. Temporal quantification of fluorescent Pseudomonas syringae pv. phaseolicola colony development correlated with in-planta bacterial multiplication (measured as CFU/ml) and is, therefore, an effective means of monitoring Pseudomonas syringae pv. phaseolicola endophytic colonization and survival in $P$. vulgaris. We present advances in the application of confocal microscopy for in-planta visualization of Pseudomonas syringae pv. phaseolicola colony development in the leaf mesophyll to show how the HR defense response greatly affects colony morphology and bacterial survival. Unexpectedly, the presence of PPHGI-1 was found to cause a reduction of colony development in susceptible $P$. vulgaris $\mathrm{CW}$ leaf tissue. We discuss the evolutionary consequences that the acquisition and retention of PPHGI-1 brings to Pseudomonas syringae pv. phaseolicola in planta.
\end{abstract}

Pseudomonas syringae strains are gram-negative bacteria that infect a wide variety of plants, causing necrotic symptoms in leaves, stems, and fruit. Pseudomonas syringae are divided into pathovars depending on plant-host range (Taylor et al. 1996). The primary mechanism of plant defense against Pseudomonas syringae is a basal defense response (Jones and Dangl 2006) that is induced upon detection of conserved microbe-associated molecular patterns (MAMPs), such as flagellin, lipopolysaccharide, or elongation factor Tu (Felix et al. 1999; Kunze et al. 2004; Zeidler et al. 2004). Pseudomonas syringae can manipulate their host by delivering an array of effector proteins into the host cytoplasm that inactivate plant surveillance mechanisms and signal transduction pathways, thereby allowing bacterial

Corresponding author: D. L. Arnold; Telephone: +44 011732 83819; Email: dawn.arnold@uwe.ac.uk growth. In the case of Pseudomonas syringae pv. phaseolicola, many plants have evolved a second mechanism of plant defense in which resistance $(R)$ proteins recognize a subset of these bacterial effector proteins, the avirulence (Avr) proteins, and this interaction (R-Avr) triggers a hypersensitive reaction (HR) (Alfano and Collmer 2004; Jones and Dangl 2006). Analysis of the molecular genetics of the R-Avr interactions between the bean pathogen Pseudomonas syringae pv. phaseolicola and its host plant includes the identification and characterization of a number of Pseudomonas syringae-derived $a v r$ genes carried by the bacterium (Taylor et al. 1996). One of these avr genes, hopARl (formerly $a v r P p h B$ ) (Lindeberg et al. 2005), leads to the activation of the HR in bean cultivar Tendergreen (TG), which carries the $R 3$ resistance gene (Jenner et al. 1991).

In Pseudomonas syringae pv. phaseolicola 1302A (race 4), hopARl is located on a 106-kb genomic island (GI) designated PPHGI-1 (Pitman et al. 2005). PPHGI-1 has a number of classic features described in other bacterial GI; it is present in the genomes of some strains but not others and is flanked by specific DNA sequences that contain direct repeats or tRNA loci. It also carries genes coding for genetic mobility, such as phage genes, insertion sequence elements, integrases, and transposases (Hacker and Kaper 2000). We have previously shown that the complete episomal island of PPHGI-1 is able to transfer between strain 1302A (race 4) to strain 1448A (race 6) by transformation both in planta and in extracted $P$. vulgaris apoplastic fluids (Lovell et al. 2009). The significant phenotypic difference between strains $1448 \mathrm{~A}$ and $1302 \mathrm{~A}$ is that $1448 \mathrm{~A}$ contains no known functional $a v r$ genes and therefore causes disease on all bean cultivars (Mansfield et al. 1994). Furthermore, it has been shown that, under R3-HopAR1-mediated HR conditions in TG, PPHGI-1 is lost from the genome of Pseudomonas syringae pv. phaseolicola $1302 \mathrm{~A}$ during repeated infection of $P$. vulgaris, and this leads to the evolution of a virulent Pseudomonas syringae pv. phaseolicola strain (referred to as strain RJ3) that no longer triggers this HR (Pitman et al. 2005). Loss of PPHGI-1 is found in more than $70 \%$ of bacteria recovered after three passages in TG (equivalent to 21 days in planta); however, in the susceptible cultivar Canadian Wonder (CW), little or no PPHGI-1 loss occurs. Although PPHGI-1 has been sequenced (GenBank accession AJ870974), we know little about the possible function of the GI in Pseudomonas syringae pv. phaseolicola.

The use of fluorescent reporter proteins in plant biology is well established, but such probes continue to be compromised by overlapping autofluorescence emission spectra from leaf and root tissue. In plant vascular tissues, autofluorescence from cell 
wall-associated phenolics occurs at wavelengths between 490 and $620 \mathrm{~nm}$, whereas chlorophyll fluorescence is most prevalent between 650 and $770 \mathrm{~nm}$ (Chapman et al. 2005). In practice, this means that the imaging of green fluorescent protein (GFP) is most problematic in roots, whereas red fluorescent proteins (RFP) can be difficult to discriminate in tissues containing many chloroplasts (Chapman et al. 2005). Nonetheless, fluorescent proteins have been used extensively in studies of epiphytic and endophytic bacterial colonization (Bloemberg et al. 2000; Compant et al. 2005; Dulla and Lindow 2008; Elbeltagy et al. 2001; Han et al. 2008). Badel and associates (2002) used GFP for imaging and quantification of in-planta colony formation to examine differences in colonization between Pseudomonas syringae pv. tomato and hopPtoA mutants in Arabidopsis. This study measured GFP colony diameter (and assumed spherical colony formation) to show mutations in hopPtoA redundantly contributed to in-planta colony formation.

The plant apoplast consists of the intercellular space in the plant tissue (including the cell wall) that is outside the plasma membrane, through which nutrients and water can freely diffuse (Abramovitch et al. 2006). The apoplast is the primary site of Pseudomonas syringae pv. phaseolicola colonization and survival when nutrients are obtained directly from apoplastic fluid. It is also within this microenvironment that bacteria triggering defenses are exposed to antimicrobial factors (Rico and Preston 2008). The HR causes plant tissue collapse and the release of antimicrobial compounds that greatly affect the survival of invading Pseudomonas syringae pv. phaseolicola strains (Jambunathan et al. 2001; Whalen et al. 1991; Wright and Beattie 2004), and the timing and severity of the HR varies depending on the direct or indirect R-Avr interactions (Kamoun et al. 1999).

In addition to visual symptoms of HR being the distinct necrosis of plant tissue, the accumulation of autofluorescent compounds is also characteristic of HR lesions (Bennett et al. 1996; Yu et al. 1998). Such HR autofluorescence is primarily associated with accumulation of phenolic compounds (Bennett et al. 1996; Kamoun et al. 1999; Kombrink and Schmelzer 2001). This HR-associated autofluorescence, in addition to emission from lignin and chlorophyll (Chapman et al. 2005), severely limits the application of confocal microscopy for the in-planta imaging of selected fluorophores under HR-inducing conditions. To combat such problems, fluorophores with im- proved biophysical properties have been developed (Chapman et al. 2005), and advances in confocal microscopic imaging technology continue to provide improvements of in-planta image acquisition. Newer confocal microscopes have optimized imaging capabilities, such as the acoustic optical tunable filters (AOTF) and acoustic optical beam splitters (AOBS) used to refine collected emission spectra and rapidly change excitation wavelengths, respectively (Saggaua 2006). A valuable application for such confocal microscopic advances in plant biology is to eliminate or minimize detection of autofluorescence emitted by both healthy plant tissue and plants undergoing the HR.

Here, we have utilized fluorescent proteins and confocal microscopy with AOTF and AOBS to investigate Pseudomonas syringae pv. phaseolicola survival in the apoplast of $P$. vulgaris, gaining insight into the temporal development of in-planta colony formation within both susceptible and resistant cultivars of $P$. vulgaris (CW and $\mathrm{TG}$, respectively). In particular, we examined one or more in-planta effects of the R3-HopAR1mediated HR on colony establishment and distribution of Pseudomonas syringae pv. phaseolicola strains (with and without PPHGI-1) in the $P$. vulgaris leaf apoplast.

\section{RESULTS}

Development of fluorescently labeled strains.

Constitutively expressed fluorescent reporter genes (either eCFP, eGFP, eYFP, or dsRFP [enhanced cyan, green, yellow, and red fluorescent proteins, respectively]) were introduced into the chromosome of Pseudomonas syringae pv. phaseolicola strains 1302A and 1448A, using a Tn7 delivery system (Lambertsen et al. 2004). In addition to the brightest expressing constructs being selected, all strains with introduced fluorescent proteins (Table 1) were only used in this study if they retained progenitor phenotypes with respect to in vitro and inplanta growth rates, HR and disease phenotypes on TG and CW leaves and pods, plasmid profiles, in vitro PPHGI-1 excision, and the expected rates of PPHGI-1 loss via passaging through TG (Pitman et al. 2005).

\section{In planta confocal microscopy of infiltrated Pseudomonas syringae pv. phaseolicola strains.}

To assess the detectable levels of in-planta fluorescence of individual Pseudomonas syringae pv. phaseolicola strains (Ta-

Table 1. Plasmids and bacterial strains

\begin{tabular}{|c|c|c|}
\hline Name & Genotype $^{\mathrm{a}}$ & Reference \\
\hline \multicolumn{3}{|l|}{ Plasmids } \\
\hline pUXBF13 & Helper plasmid, providing the $\mathrm{Tn} 7$ transposase proteins, $A p^{\mathrm{r}}$ & Bao et al. 1991 \\
\hline pRK2013 & Conjugation helper plasmid, $\mathrm{Km}^{\mathrm{r}}$ & Figurski et al. 1979 \\
\hline AKN132 & dsRFP, $\mathrm{Ap}^{\mathrm{r}}, \mathrm{Gm}^{\mathrm{r}}$ & Lambertsen et al. 2004 \\
\hline AKN100 & $\mathrm{eGFP}, \mathrm{Ap}^{\mathrm{r}}, \mathrm{Gm}^{\mathrm{r}}$ & Lambertsen et al. 2004 \\
\hline AKN069 & eYFP, $\mathrm{Ap}^{\mathrm{r}}, \mathrm{Gm}^{\mathrm{r}}$ & Lambertsen et al. 2004 \\
\hline AKN033 & $\mathrm{eCFP}, \mathrm{Ap}^{\mathrm{r}}, \mathrm{Gm}^{\mathrm{r}}$ & Lambertsen et al. 2004 \\
\hline \multicolumn{3}{|l|}{ Escherichia. coli } \\
\hline 39R861 & Containing plasmids of known molecular weight for plasmid profiling & Threllfall et al. 1986 \\
\hline \multicolumn{3}{|c|}{ Pseudomonas syringae pv. phaseolicola strains } \\
\hline $1302 \mathrm{~A}$ & Wild-type strain, race 4 & Taylor et al. 1996 \\
\hline 1302A-eCFP & 1302A::Tn7-eCFP, Gm ${ }^{r}$ & This study \\
\hline 1302A-eGFP & 1302A::Tn7-eGFP, Gm ${ }^{r}$ & This study \\
\hline 1302A-eYFP & 1302A::Tn7-eYFP, Gm ${ }^{\mathrm{r}}$ & This study \\
\hline 1302A-dsRFP & 1302A::Tn7-dsRFP, Gmr & This study \\
\hline RJ3 & 1302A with PPHGI-1 loss & Jackson et al. 2000 \\
\hline RJ3-eYFP & RJ3::Tn7-eYFP, Gm & This study \\
\hline $1448 \mathrm{~A}$ & Wild-type strain, race 6, Rif $^{r}$ & Mansfield et al. 1994 \\
\hline 1448A-eYFP & 1448A::Tn7-eYFP, $\mathrm{Gm}^{\mathrm{r}}$ & This study \\
\hline 1448A::PPHGI-1 & 1448ARif containing PPGHI- $1, \mathrm{Km}^{\mathrm{r}}$ & Lovell et al. 2009 \\
\hline 1448A::PPHGI-1-eYFP & 1448A::PPHGI-1-Tn7-eYFP, $\mathrm{Km}^{\mathrm{r}}, \mathrm{Gm}^{\mathrm{r}}$ & This study \\
\hline
\end{tabular}

${ }^{\mathrm{a}} \mathrm{Ap}^{\mathrm{r}}, \mathrm{Gm}^{\mathrm{r}}$, Rif ${ }^{\mathrm{r}}$, and $\mathrm{Km}^{\mathrm{r}}$ indicate resistance to ampicillin, gentamicin, rifampicin, and kanamycin, respectively. dsRFP, eGFP, eYFP, and eCFP $=$ red and enhanced green, yellow, and cyan flourescent protein, respectively. 
ble 1), various concentrations of inocula were syringe-infiltrated into the mesophyll layer of $P$. vulgaris cv. CW or TG, or both, and plants were maintained under glasshouse conditions for 24 to $144 \mathrm{~h}$ before sections of leaf tissue were removed for confocal observation.

\section{Colony formation is reduced in TG.}

The first observation during confocal microscopy of fluorescent Pseudomonas syringae pv. phaseolicola 1302A strains (containing avirulence gene hopARl) infiltrated into TG leaf tissue (causing a R3-HopAR1-mediated HR) was the development of small, dense 1302A-eYFP colonies among the collapsed plant tissue (Fig. 1A) compared with the larger flourishing colonies in non-HR environments, e.g., strain RJ3 (with loss of hopARl) in TG (Fig. 1B). These results are consistent with current knowledge that the HR causes reduced in-planta bacterial growth (recorded as $\mathrm{CFU} / \mathrm{ml}$ ).
Fluorophore detection in TG.

In addition to reduced colony morphology of hopARl-containing strains in TG (Fig. 1A), results also showed the R3HopAR1-mediated HR caused the accumulation of many autofluorescent compounds. The severity of TG autofluorescence increased with higher Pseudomonas syringae pv. phaseolicola 1302A infiltration concentrations (Fig. 1C and D). Both eGFP and eYFP could be effectively visualized within the HR autofluorescence; however, eYFP exhibited brighter fluorophore emission and thus enabled higher-quality confocal image acquisition of Pseudomonas syringae pv. phaseolicola colony formation. The $P$. vulgaris R3-HopAR1-mediated HR autofluorescence showed spectral overlap primarily with dsRFP, and therefore, dsRFP was very difficult to visualize. eCFP was also difficult to visualize because of its low quantum yield $(3,000$ compared with 24,300 in eYFP), as the increased parameters required to enhance eCFP detection also meant any HR auto-
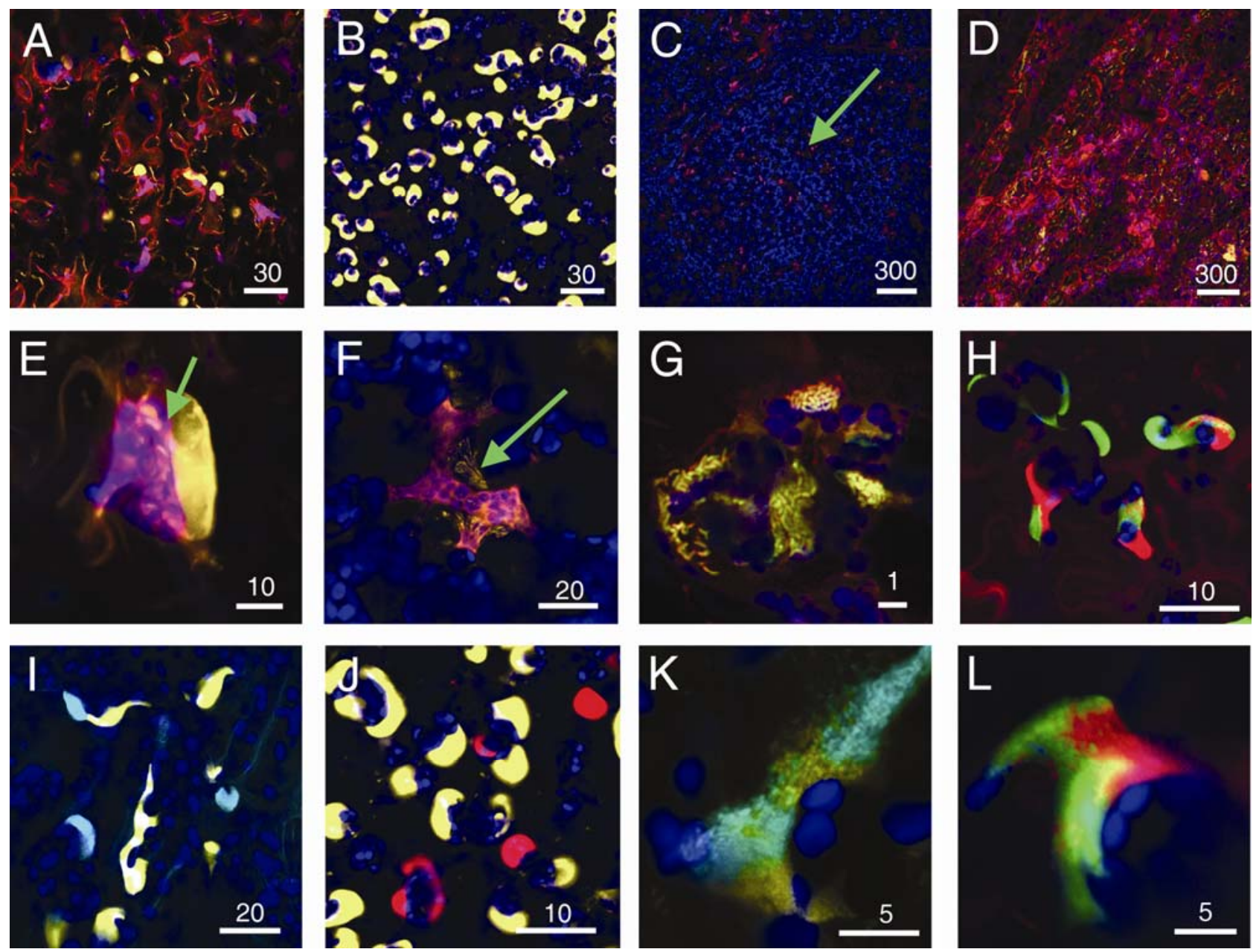

Fig. 1. Confocal images showing various fluorescent Pseudomonas syringae pv. phaseolicola strains forming in-planta colonies in Phaseolus vulgaris leaf tissue. When Pseudomonas syringae pv. phaseolicola 1302A-eYFP is infiltrated into cv. Tendergreen (TG), the R3-HopAR1-mediated hypersensitive-response (HR) causes tissue collapse resulting in the accumulation of autofluorescent compounds that are visualized (as a pink discoloration) in confocal microscopy. A, The TG R3-HopAR1-mediated HR makes visualization of fluorophores difficult and only eYFP (shown here) and eGFP (enhanced yellow and green fluorescent protein, respectively) can be visualized efficiently. B, Strain RJ3 (lacking hopARl) in TG infiltrated identically as A (note the flourishing colony development in a non-HR environment). C, The TG $R 3$-HopAR1-mediated HR can be visualized as small localized regions (arrow) when infiltrated with low pathogen concentrations $(8 \times$ $\left.10^{4} \mathrm{CFU} / \mathrm{ml}, 72 \mathrm{~h}\right)$ or $\mathbf{D}$, as total tissue collapse when infiltrated with a high pathogen concentration $\left(8 \times 10^{7}, 72 \mathrm{~h}\right)$. E, At lower infiltration concentrations $(8 \times$ $10^{4} \mathrm{CFU} / \mathrm{ml}$ ), the HR in TG could be minimized (as in C) to permit imaging of individual Pseudomonas syringae pv. phaseolicola $1302 \mathrm{~A}-\mathrm{eYFP}$ colonies adjacent (arrow) to collapsing plant tissue undergoing the R3-HopAR1-mediated HR. F, Selected 1302A-eYFP colonies adjacent to TG HR tissue were observed to rupture (arrow) after approximately $144 \mathrm{~h}$ and G, release individual bacteria into the plant apoplast. Mixed Pseudomonas syringae pv. phaseolicola 1302A fluorescent strains $\left(8 \times 10^{5} \mathrm{CFU} / \mathrm{ml}\right.$ each) are readily visualized in non-HR cv. Canadian Wonder (CW) leaf tissue as either $\mathbf{H}$, 1302A-eGFP and 1302A-dsRFP, I, 1302A-eCFP (enhanced cyan fluorescent protein) and 1302A-YFP, or J, 1302A-eYFP and 1302A-dsRFP. Although strains predominantly formed individual colonies emitting one fluorescence (e.g., H through J), mixed colonies expressing both fluorescent proteins were also observed: K, 1302A-eCFP and 1302AeYFP; L, 1302A-eGFP and 1302A-dsRFP. All confocal images were assigned false color (eCFP, cyan; eGFP, green; eYFP, yellow; dsRFP, red; plant tissue, blue; and HR autofluorescence, an overlay of cyan, red, and blue channels to give pink). Size bars are in micrometers. 
fluorescence was similarly enhanced. From these results, it was deemed that the optimal conditions for visualizing Pseudomonas syringae pv. phaseolicola colony development under $P$. vulgaris R3-HopAR1-mediated $\mathrm{HR}$ conditions was to infiltrate TG with strain 1302A-eYFP at $8 \times 10^{4} \mathrm{CFU} / \mathrm{ml}$, which then enabled efficient in-planta confocal observation of colony formation adjacent to plant cells undergoing the HR (Fig. 1E).

\section{Observation of in-planta colony dispersal in TG.}

Within the mesophyll of TG undergoing the R3-HopAR1mediated HR, single cells were observed to emerge from ruptured Pseudomonas syringae pv. phaseolicola 1302A colonies into the apoplast after approximately $144 \mathrm{~h}$ (Fig. 1F and $\mathrm{G})$. Such bacterial dispersal was visualized in both samples mounted in water and in dry-mounted tissue samples. Dispersal was rarely observed in $\mathrm{CW}$ tissue, even after prolonged incubation.

\section{Fluorophore detection in CW.}

By contrast, confocal microscopy of fluorescent Pseudomonas syringae pv. phaseolicola 1302A strains infiltrated into CW leaf tissue (no R3-mediated HR) showed eGFP, dsRFP, eYFP, and eCFP emissions were readily distinguishable from plant tissue (individual data not shown; however, Figure $1 \mathrm{H}$ to $\mathrm{L}$ shows representative fluorescence recovery in $\mathrm{CW}$ ).

\section{In planta confocal microscopy of mixed infiltrations} of Pseudomonas syringae pv. phaseolicola strains.

Mixtures of Pseudomonas syringae pv. phaseolicola strains were infiltrated as above to determine the efficacy of confocal visualization of multiple fluorescent bacteria within $P$. vulgaris, using the AOTF of the Leica microscope (Leica, Wetzlar, Germany).

$T G$. When mixtures of Pseudomonas syringae pv. phaseolicola strains were infiltrated into $\mathrm{TG}$, similar imaging limitations as described above were encountered when the HR was initiated by one or both of the strains containing hopARl. Minimizing the HR severity was achieved by lowering the infiltration concentration of strains containing hopARl to $8 \times 10^{4} \mathrm{CFU} / \mathrm{ml}$ or less. Although this improved imaging of both eCFP and dsRFP strains, it also subsequently reduced the number of Pseudomonas syringae pv. phaseolicola colonies formed and reduced the HR intensity affecting Pseudomonas syringae pv. phaseolicola colony formation. These findings confirm that, although both eGFP and eYFP are optimal fluorescent proteins to use in the TG R3HopAR1-mediated HR, they cannot be used together in planta, due to limitations in accurately differentiating fluorophore emission from close overlapping spectra (Zimmermann et al. 2003).

$C W$. Successful fluorescence recovery was achieved from mixed infiltrations of Pseudomonas syringae pv. phaseolicola 1302A fluorescent strains $\left(8 \times 10^{5} \mathrm{CFU} / \mathrm{ml}\right.$ each $)$ in $\mathrm{CW}$. Mixed Pseudomonas syringae pv. phaseolicola strains were visualized to either i) from individual colonies emitting predominantly one fluorescence (Fig. $1 \mathrm{H}$ to $\mathrm{J}$ ), ii) from mixed colonies with cells expressing both fluorophores (Fig. 1K and L), or iii) both. In order to obtain clear images of mixtures, it was necessary to balance the sensitivity of detection of fluorophores. For example, as illustrated in Figure 1H, eGFP was detectable at low sensitivity, whereas the signals for dsRFP emission were maximized (thus simultaneously enhancing plant autofluorescence). The clearest consistent differential between Pseudomonas syringae pv. phaseolicola strains in $\mathrm{CW}$ was achieved by combining eYFP- and eCFP-labeled bacteria (Fig. 1I).
Quantification of confocal colony image data (CCID) and comparison with bacterial growth rate $(\mathrm{CFU} / \mathrm{ml})$.

Although both eGFP and eYFP could be effectively visualized within the HR autofluorescence, eYFP was chosen for routine use because of its higher quantum yield (eYFP of 24,300 compared with eGFP of 16,100). Pseudomonas syringae pv. phaseolicola colonies expressing eYFP provided high-quality confocal image acquisition, with good contrast between eYFP and plant tissue (Fig. 2A to C). This enabled ImageJ software (Abramoff et al. 2004) quantification of threshold data values to calculate the percentage of colony area within the imaged plant tissue. To determine the relationship between eYFP-CCID and the bacterial growth rate data of viable eYFP cells present, infiltrated tissue samples were collected immediately adjacent to each other-one for CCID and one for establishment of the bacterial growth rate. Serial dilutions of ground tissue extracts grown on agar supplemented with gentamicin (Gm, for selection of eYFP) showed $100 \%$ of gentamicin-resistant colonies recovered exhibited positive eYFP fluorescence. ImageJ CCID based on colony area showed equivalent trends to Pseudomonas syringae pv. phaseolicola bacterial growth rate recovered from leaves (Fig. 3), and therefore, CCID was considered a rapid and accurate way to generate statistical data for the comparison of Pseudomonas syringae pv. phaseolicola survival in $P$. vulgaris $\mathrm{CW}$ and $\mathrm{TG}$.
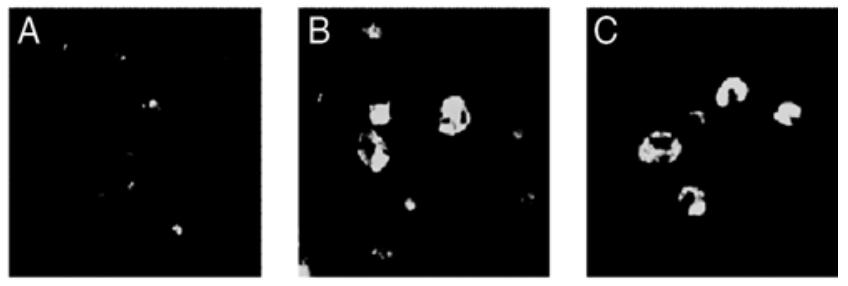

D

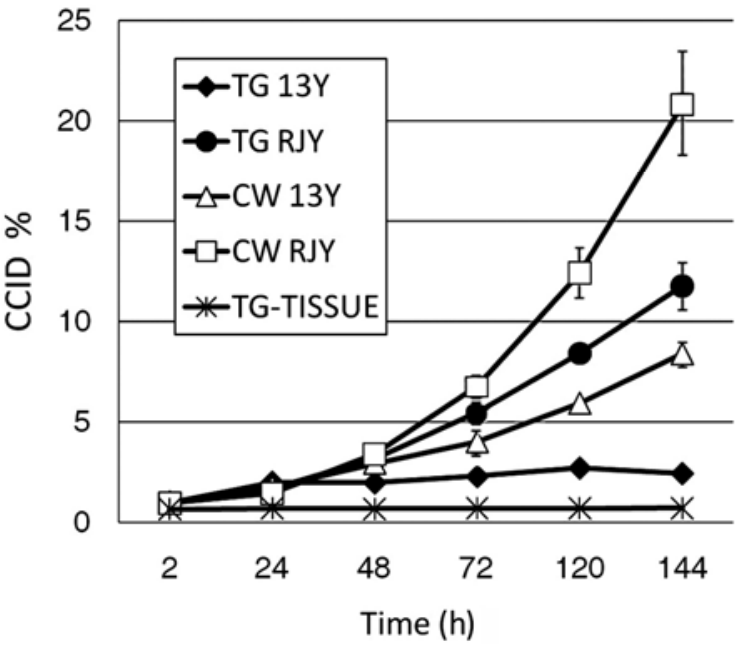

Fig. 2. The R3-HopAR1-mediated hypersensitive response (HR) environment causes restricted colony development of Pseudomonas syringae pv. phaseolicola 1302A (containing hopARl). Images subjected to threshold analysis using ImageJ show that A, strain 1302A-eYFP colony morphology is small and compact when infiltrated into Tendergreen (TG) compared with B, strain RJ3-eYFP (1302A with loss of PPHGI-1 and, therefore, hopARl) grown in TG, which produces larger flourishing colonies. C, 1302A-eYFP exhibits flourishing colonies similar to strain RJ3-eYFP when grown in CW (no R3-HopAR1-mediated HR). eYFP colony expression was analyzed with ImageJ software to provide confocal colony image data (CCID) representing the percent eYFP colony area within the Phaseolus vulgaris leaf apoplast. D, Temporal CCID collection from single-strain infiltrations $\left(1.6 \times 10^{6} \mathrm{CFU} / \mathrm{ml}\right)$ over $144 \mathrm{~h}$. Data are means \pm standard error of the mean ( $n=36$ for each timepoint). 
Pseudomonas syringae pv. phaseolicola 1302A shows reduced in-planta growth compared

with strain RJ3 in both TG and CW leaves.

We examined the effect of PPHGI-1 on colony development in susceptible and resistant plants. The temporal CCID collected for strains 1302A-eYFP (containing PPHGI-1 with hopARl) and RJ3-eYFP (a 1302A strain that has lost PPHGI-1) within TG (containing $R 3$ ) and CW (no $R 3$ ) are shown in Figure 2D. Results confirmed that, after 144 h, Pseudomonas syringae pv. phaseolicola $1302 \mathrm{~A}$ colonies have a $76 \%$ decrease in colony formation in TG undergoing the R3-HopAR1-mediated HR compared with strain RJ3. In CW interestingly, strain RJ3 also had a $34 \%$ increase in colony development compared with Pseudomonas syringae pv. phaseolicola 1302A, even in the absence of the R3-HopAR1-mediated HR. Recovered bacterial growth rate results supported CCID (Fig. 3) in which i)
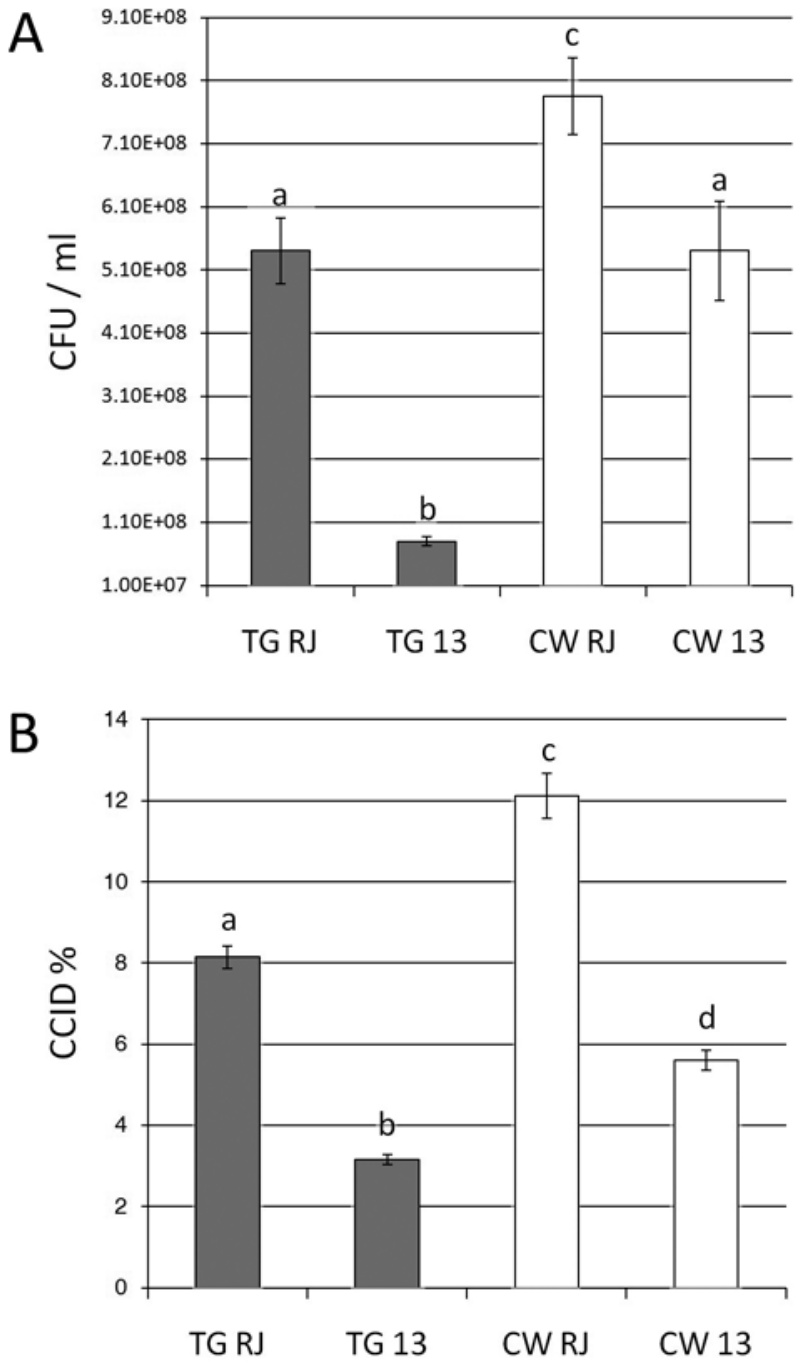

Fig. 3. Comparison of in-planta colony-forming units recovered (measured in CFU/ml) and confocal colony image data (CCID) from infiltrated Pseudomonas syringae pv. phaseolicola strains $\left(1.6 \times 10^{6} \mathrm{CFU} / \mathrm{ml}\right)$ after $120 \mathrm{~h}$. A, Bacterial growth found in 1302A-eYFP (13) and RJ3-eYFP (RJ) from Tendergreen (TG) and Canadian Wonder (CW) leaf tissue. B, Data represents the percent eYFP expression from 1302A-eYFP and RJ3-eYFP in TG and CW. The similar trends between A and B suggests CCID is a good representation of in-planta bacterial growth. Data are means \pm standard error of the mean ( $n=10$ for in-planta bacterial growth and $n=36$ for CCID). For both graphs, analysis of variance showed significant differences between strains and between cultivars $(P<0.0001$ and $\mathrm{df}=1$ for both tests); significant differences among sample means were revealed by Student's $t$-test $(P=0.05)$ and are indicated by different letters above bars. growth was better in CW than TG for both strain RJ3-eYFP and 1302A-eYFP, and ii) strain RJ3-eYFP displayed better growth than 1302A-eYFP in either TG or CW. Significantly, no growth rate differences were observed between the strains under varying in vitro growth conditions (data not shown).

\section{Comparison of different Pseudomonas syringae pv. phaseolicola strains containing PPHGI-1.}

Results presented in Figure 3 suggest PPHGI-1 (containing hopARl) negatively affects both in-planta growth rate (CFU/ $\mathrm{ml}$ ) and colony formation (CCID) in both resistant (TG) and susceptible (CW) tissue. To confirm the effect of PPHGI-1, we compared different Pseudomonas syringae pv. phaseolicola strains, strain 1448A (race 6) and strain 1448A::PPHGI-1 (containing a copy of PPHGI-1 transferred from 1302A [Lovell et al. 2009]). Strains 1448A and 1448A::PPHGI-1 were chromosomally labeled with Tn7 eYFP and were infiltrated into TG and CW. Data presented in Figure 4 show that the presence of PPGHI-1 in strain 1448A reduced colony size (by $72 \%$ in TG and $31 \%$ in $\mathrm{CW}$ ). By contrast, no differences in multiplication between strains 1448A and 1448A::PPHGI-1 were observed in vitro using various growth media (data not shown).

\section{Pseudomonas syringae pv. phaseolicola strains do not migrate significantly from infiltration sites.}

To determine movement of fluorescent Pseudomonas syringae pv. phaseolicola strains within inoculated TG and $\mathrm{CW}$ plants, we examined sections of plants outside the infiltration site from i) immediately adjacent to infiltration, ii) secondary leaf tissue, iii) leaf stems, and iv) root tissue. All samples were imaged and no fluorescent colony formation was detectable. Furthermore, the same samples were homogenized, and analysis failed to recover bacteria. These results show that infiltrated Pseudomonas syringae pv. phaseolicola strains remain localized to the area of inoculation and, if single cell dispersal and re-establishment of colonies occurs in planta, such movement is restricted within the microenvironment of the infiltrated apoplast.

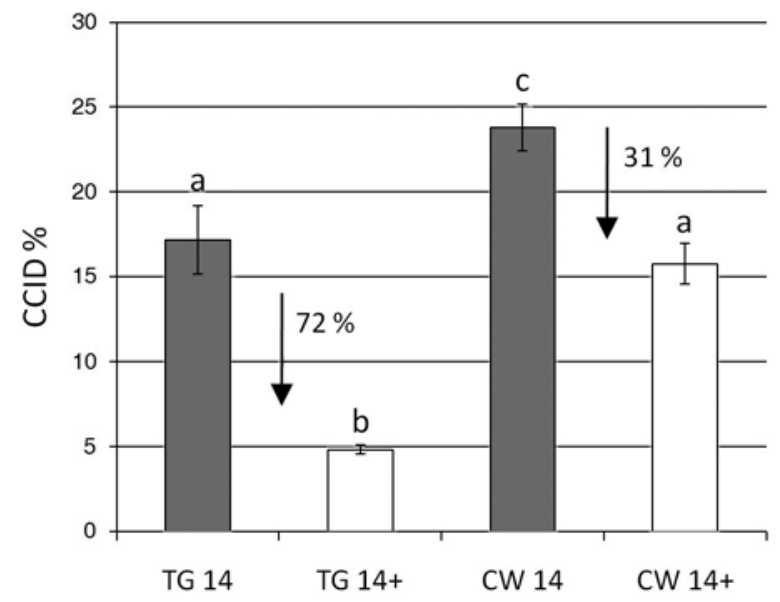

Fig. 4. Comparison of in-planta confocal colony image data (CCID) between Pseudomonas syringae pv. phaseolicola 1448A strains (with and without PPHGI-1) after $120 \mathrm{~h}$. CCID represents percent Pseudomonas syringae pv. phaseolicola eYFP expression in Phaseolus vulgaris leaf apoplast from single-strain infiltrations $\left(1.6 \times 10^{6} \mathrm{CFU} / \mathrm{ml}\right)$. Data are means \pm standard error of the mean ( $n=36$ each), and numbers above bars represent percent decrease as a result of the presence of PPHGI-1 in 1448A. Analysis of variance showed significant differences between strains and between cultivars $(P<0.0001$ and $\mathrm{df}=1$ for both tests $)$; significant differences among sample means were revealed by Student's $t$-test $(P=0.05)$ and are indicated by different letters above bars. $\mathrm{CW}=$ Canadian Wonder; $\mathrm{TG}=$ Tendergreen; 14 = 1448A-eYFP; 14+ = 1448A::PPHGI-1-eYFP (a 1448A strain that has acquired PPHGI-1 by horizontal transfer). 
Infiltration concentration significantly affects Pseudomonas syringae pv. phaseolicola colony formation during the HR.

Initial infiltration concentration in TG affected colony development by Pseudomonas syringae pv. phaseolicola strains harboring hopARl (Fig. 5). When high inoculum concentrations $\left(1.6 \times 10^{8} \mathrm{CFU} / \mathrm{ml}\right)$ of strain $1302 \mathrm{~A}$-eYFP were infiltrated into TG tissue, large colony-area development occurred in the mesophyll after $120 \mathrm{~h}$, whereas low inoculum concentrations resulted in much smaller colony-area development, a $30 \%$ decrease at $1.6 \times 10^{6} \mathrm{CFU} / \mathrm{ml}$ and $59.3 \%$ decrease at $1.6 \times 10^{4} \mathrm{CFU} / \mathrm{ml}$ (Fig. 5). No significant differences were observed between infiltration concentration and colony development of strain RJ3 (no hopARl) in TG.

\section{DISCUSSION}

It is well-established that HR greatly affects endophytic bacterial survival and that a higher inoculum of avirulent bacteria infiltrated into a resistant host, such as Pseudomonas syringae pv. phaseolicola 1302A into TG, will cause a more severe host HR response. Here, we utilized fluorescent proteins and confocal microscopy to investigate phenotypic variation in colony formation by avirulent bacteria within the hostile environment of the plant mesophyll undergoing the HR.

Constitutive fluorescent reporter genes (either eCFP, eGFP, eYFP, or dsRFP) were chromosomally introduced into Pseudomonas syringae pv. phaseolicola strains 1302A and 1448A, using a Tn7 delivery system (Lambertsen et al. 2004) that inserts site-specifically downstream of the terminal part of glmS encoding glucosamine synthetase, required for cell-wall synthesis (Vogler et al. 1989). This Tn7 insertion does not disrupt the $g \operatorname{lm} S$ gene (Gringauz et al. 1988) and, indeed, no Pseudomonas syringae pv. phaseolicola fluorescent constructs created in this study showed any differences in phenotype compared with their progenitors.

We utilized technological advancements in confocal microscopy of AOTF and AOBS to improve further understanding of Pseudomonas syringae pv. phaseolicola bacterial colonization in planta. The standard band-pass filters available on the Zeiss Axiovert did not provide sufficient discrimination of the spectral overlap of HR autofluorescence and fluorescent proteins. Therefore, the high quality in-planta resolution obtained in this study depended greatly on the AOTF of the Leica TCS-SP2DM IRE2, which enabled real-time adjustment of detection filter parameters to minimize the unwanted HR autofluorescence while maximizing fluorescent protein detection. The rapid change of excitation wavelengths using AOBS of the Zeiss Axiovert during CCID data collection enabled efficient highthroughput scanning of live plant tissue samples with minimal damage to either bacterial colonies or plant cells due to overexposure of laser intensity. Such results confirm that the advances in confocal imaging technology continue to improve in-planta image acquisition.

Autofluorescence accumulating in TG as a result of the R3HopAR1-mediated HR complicated detection of dsRFP and eCFP emission from bacteria. Although eGFP proved effective for visualization within the HR autofluorescence, eYFP was chosen for routine use because of its higher quantum yield, which enabled high-quality confocal image acquisition. Furthermore, the higher quantum yield of eYFP was beneficial because it allowed colony detection at lower laser excitation intensities, which resulted in less plant-tissue damage. Pseudomonas syringae pv. phaseolicola colonies expressing eYFP provided good contrast (Fig. 2A to $\mathrm{C}$ ) for obtaining quantitative CCID on the percentage of the area of Pseudomonas syringae pv. phaseolicola colony development within the im- aged mesophyll. Because CCID is dependent on aggregation and growth of fluorescent Pseudomonas syringae pv. phaseolicola cells into colonies, it is possible that individual cells were not fully represented by the confocal detection methods used in this study. However, because the CCID obtained in this study showed equivalent trends to Pseudomonas syringae pv. phaseolicola bacterial growth rate isolated in planta (Fig. 3), CCID was considered a rapid and accurate way to record and compare Pseudomonas syringae pv. phaseolicola survival in planta.

In addition to providing quantitative information, imaging allowed the shape of colonies and bacterial dispersal to be examined. During the HR, Pseudomonas syringae pv. phaseolicola colonies were generally compact and observed to be restricted in size compared with non-HR colony development (Fig. 2A to C). However, such colonies were often observed to become fragmented and release bacterial cells after prolonged incubation in TG (Fig. 1G). The breakdown of colony structure would expose individual bacteria directly to the adverse conditions within the apoplast. The dynamics of colony dispersal as indicated from this work may influence the evolution of new virulent strains in planta, as has been suggested previously (Arnold et al. 2007). Such exposure may kill off the avirulent bacteria and is likely to enhance the deletion of PPHGI-1 and, therefore, increase selection for cells lacking avirulence genes such as hopARl. The detection of differentially labeled strains was also optimized using eYFP and dsRFP, but using mixtures required a compromise on excitation and emission parameters. We are currently developing strains suitably tagged in both PPHGI-1 and the chromosome to attempt to examine loss of the GI within plant tissues.

Imaging data consistently showed that Pseudomonas syringae pv. phaseolicola 1302A containing PPHGI-1 exhibited reduced colony formation compared with strain RJ3 without PPHGI-1 (Figs. 2D and 3). This result was expected in TG with 1302A harboring PPHGI-1 (and therefore hopARl), in which induc-

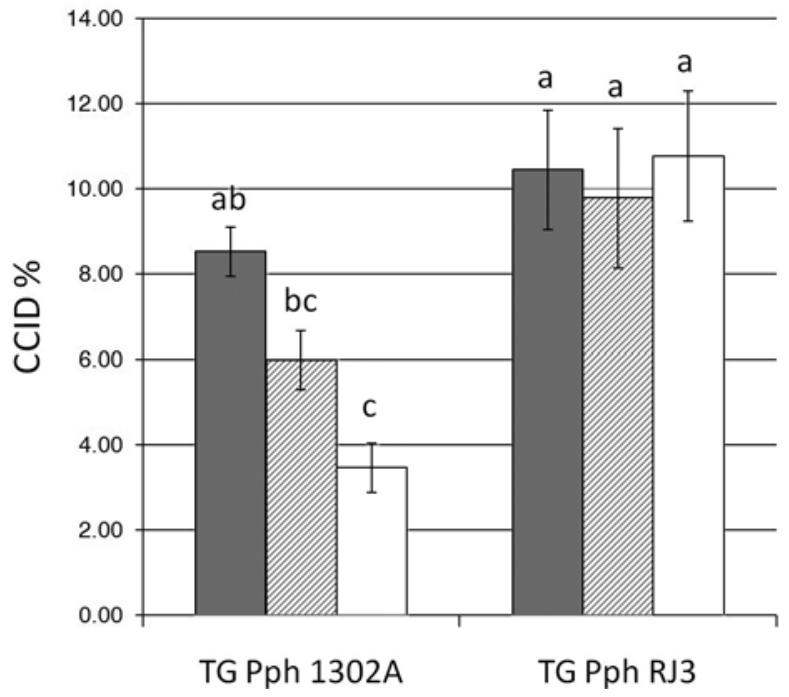

Fig. 5. Comparison of in-planta confocal colony image data (CCID) from varying infiltration concentrations after $120 \mathrm{~h}$. Results are standardized to an equivalent starting infiltration concentration $\left(1.6 \times 10^{6} \mathrm{CFU} / \mathrm{ml}\right)$ to allow direct comparison after $120 \mathrm{~h}$. Pseudomonas syringae pv. phaseolicola 1302A (enhanced yellow flourescent protein [eYFP]-labeled and containing hopAR1) shows greatly reduced colony formation at low infiltration concentrations compared with strain RJ3 (eYFP-labeled and lacking hopARl) in Tendergreen (TG). Data are means \pm standard error of the mean $(n=12$ each). Analysis of variance showed a significant effect of infiltration concentration on 1302A-eYFP compared with strain RJ3-eYFP $(P=0.0277$, df $=$ $2)$; significant differences among sample means were revealed by Student's $t$-test $(P=0.05)$ and are indicated by different letters above bars. 
tion of the R3-HopAR1-mediated HR would occur and thus create a hostile environment inhibiting Pseudomonas syringae pv. phaseolicola growth. However, reduced colony formation by $1302 \mathrm{~A}$ in $\mathrm{CW}$ was unexpected, given the lack of any known race-specific $R$ genes in this cultivar. Similar reduction in colony development was observed with 1448A harboring PPHGI-1. These observations suggest that PPHGI-1 may harbor one or more additional genes responsible for eliciting plant basal defenses in $P$. vulgaris. Although basal and $R$ gene-mediated defenses (Abramovitch et al. 2006) share some common molecular mechanisms (Sun et al. 2006), the most characteristic feature of $R$ gene-mediated defenses is induction of the HR (Lam 2004). There was no evidence of Pseudomonas syringae pv. phaseolicola strains 1302A or 1448A::PPHGI-1 showing HR-like symptoms, including accumulation of autofluorescent compounds in $\mathrm{CW}$, so reduced fitness was unlikely to be a result of a R-Avr interaction. It is possible that PPHGI-1 contains one or more genes that encode MAMPs activated in both TG and CW basal defenses and, therefore, may account for the reduced fitness of Pseudomonas syringae pv. phaseolicola strains harboring PPHGI-1. With the exception of hopARl, bioinformatic analysis of PPHGI-1 reveals no obvious candidates that would elicit known MAMP-activated basal resistance; however, there are many transmembrane pattern recognition receptors in plants that are not yet fully characterized (Jones and Dangl 2006).

Unless newly acquired GI encode their own specific regulators or are integrating into pre-existing regulatory networks (Gal-Mor and Finlay 2006), such foreign DNA acquisition may lead to an initial fitness loss of the bacterial host due to the host bacterium needing time to adapt to the acquisition of a new GI (Dobrindt et al. 2004). Because there is no evidence to show that Pseudomonas syringae pv. phaseolicola 1448A has harbored PPHGI-1 (or similar GI) previously, the effects of PPHGI-1 integration in 1448A::PPHGI-1 was regarded as de novo behavior and not the result of a previous adaptation to a long-term interaction between GI and host. Interestingly, 1448A::PPHGI-1 shared similar trends to strain 1302A (in both $\mathrm{CW}$ and $\mathrm{TG}$ ), with reduced colony formation as a result of harboring PPHGI-1, suggesting that 1302A has only recently acquired PPHGI-1 and, therefore, PPHGI-1 may be a nonadapted integrative nucleotide sequence causing an in-planta fitness compromise. It is interesting that no in vitro difference is observed between 1302A and strain RJ3 or 1448A and 1448A:: PPHGI-1, which would suggest the reduced growth is not due to the metabolic burden of harboring PPHGI-1 but, rather, a direct result of one or more plant responses.

Many of the unidentified open reading frames (ORF) in PPHGI-1 may be associated with fitness gain in the exploitation of new environmental niches (Pitman et al. 2005). The growth and survival of Pseudomonas syringae pv. phaseolicola 1302A under field conditions will involve its ability to either tolerate or escape, or both, the internal and external leaf environmental stresses, including desiccation, nutrient deprivation, exposure to ultraviolet radiation, and oxidative stress encountered both from exposure to UVA radiation and from the plant defense response. Predicted ORF identified in PPHGI-1 (Pitman et al. 2005) that could aid Pseudomonas syringae pv. phaseolicola under such situations include those encoding i) type IV pilus, known for their importance in host colonization by aiding translocation over moist surfaces by the so-called twitching motility (Mattick 2002); ii) bacteriophytochrome, belonging to a class of light-responsive proteins involved with signaling pathways in changing light levels (Davis et al. 1999); iii) SOS response and DNA repair proteins, potential candidates for UV tolerance and survival in direct sunlight (Nohmi 2006); iv) chemotaxis proteins, known to be important in plant colonization for regulating bacterial motility in response to environmental signals (Danhorn and Fuqua 2007); and v) histidine kinase and response regulators, involved in two-component systems that induce a multitude of gene-regulatory systems in response to environmental changes (Beier and Gross 2006). In addition, many novel genes are identified in PPHGI-1 that have no detectable homologs and therefore currently have unknown function. Such novel GI genes may be considered possible candidates for conferring selective advantage to the host organism (Hsiao et al. 2005) and warrant future investigation.

In conclusion, this work provides a significant contribution to the understanding of endophytic colonization by establishing efficient methodology for temporal studies of Pseudomonas syringae pv. phaseolicola colony development within the apoplast of both healthy $P$. vulgaris leaf tissue and tissue undergoing the HR. Our preliminary experiments with Arabidopsis and tomato indicate that the same imaging methods will be applicable to other bacterium-plant interactions. Furthermore, we have shown that, while GI may prove to be of great evolutionary benefits under certain environmental conditions, under others, they may be disadvantageous.

\section{MATERIALS AND METHODS}

\section{Bacterial strains and techniques.}

Bacterial strains and plasmids used in this study are listed in Table 1. Escherichia coli strains were grown at $37^{\circ} \mathrm{C}$ in Luria Bertani (LB) media (Sambrook et al. 1989) and Pseudomonas strains at $25^{\circ} \mathrm{C}$ in LB or King's B (KB) (King et al. 1954). Antibiotics were used at the following concentrations $(\mu \mathrm{g} / \mathrm{ml})$ : Gm, 10; kanamycin, 50; ampicillin, 100; nitrofurantoin (NF), 100; cycloheximide (CHX), 100; and rifampicin, 100. Polymerase chain reaction of PPHGI-1 circular intermediate and plasmid profiling of Pseudomonas syringae pv. phaseolicola strains in comparison with E. coli 39R861 were performed as described by Lovell and associates (2009). Determination of PPHGI-1 evolutionary loss by passaging through TG and determination of $\mathrm{HR}$ disease phenotypes in TG and $\mathrm{CW}$ leaves and pods was performed as by Pitman and associates (2005).

\section{Chromosomal introduction and}

visualization of fluorescent proteins.

Fluorescent protein variants (eYFP, AKN069 [Table 1]; eGFP, AKN100; eCFP, AKN033; and dsRFP, AKN132) were chromosomally introduced into 1302A and 1448A strains via the $\mathrm{Tn} 7$ transposon delivery system, as described previously by Lambertson and associates (2004). Gentamicin-resistant Pseudomonas syringae pv. phaseolicola strains (Table 1) had respective fluorophore expression in colonies confirmed using a Leica TCS4D dissecting microscope (Leica Microsystems Wetzlar $\mathrm{GmbH}$ ).

\section{In planta Pseudomonas syringae pv. phaseolicola infiltrations.}

$P$. vulgaris bean cultivars $\mathrm{TG}$ and $\mathrm{CW}$ were grown at $23^{\circ} \mathrm{C}$ $95 \%$ humidity, and artificial light was maintained for $16-\mathrm{h}$ periods within the 24-h cycle. In preparation for plant inoculations, overnight bacterial cultures were washed twice and were resuspended in one-quarter Ringers solution. Single or mixed bacterial inoculums were diluted in one-quarter Ringers to one of the following final concentrations: i) 0.6 optical density at $600 \mathrm{~nm}$ $\left(\mathrm{OD}_{600}\right)$ (approximately $\left.5 \times 10^{8} \mathrm{CFU} / \mathrm{ml}\right)$, ii) $0.1 \mathrm{OD}_{600}(8 \times$ $\left.10^{7}\right)$, iii) $1 \times 10^{-2} \mathrm{OD}_{600}\left(8 \times 10^{6}\right)$, iv) $1 \times 10^{-3} \mathrm{OD}_{600}\left(8 \times 10^{5}\right)$, v $)$ $1 \times 10^{-4} \mathrm{OD}_{600}\left(8 \times 10^{4}\right)$, or vi) $1 \times 10^{-5} \mathrm{OD}_{600}\left(8 \times 10^{3}\right)$. Desired inocula were syringe-infiltrated into the mesophyll of the primary leaf and were incubated for up to $144 \mathrm{~h}$ as required. Infiltrated leaf tissue was excised immediately prior to analysis. 
In planta confocal imaging.

Sections of infiltrated $P$. vulgaris leaves (approximately 5 $\mathrm{mm}^{2}$ ) were removed, and the slides were mounted in doubledistilled $\mathrm{H}_{2} \mathrm{O}$ (lower epidermis toward objective) under a 0.17 $\mathrm{mm}$ coverslip. The leaf mesophyll was imaged using one of two confocal microscopes. i) For high-quality image acquisition, the Leica TCS-SP2-DM IRE2 confocal laser scanning microscope (Leica Microsystems Wetzlar GmbH) with AOTF was used at $25 \times$ or $40 \times$ (objective magnification) for colony morphology and $100 \times$ for visualization of individual cell dispersal. Variable AOTF filters were used for the following fluorophores (excitation/emission): eYFP (514 nm/525 to 600 $\mathrm{nm})$, eCFP (440/465 to $495 \mathrm{~nm})$, eGFP (488/516 to $539 \mathrm{~nm})$; dsRFP (568/600 to $644 \mathrm{~nm}$ ), and for plant autofluorescence (440/650 to $785 \mathrm{~nm})$. Z-series imaging was performed at intervals of between 0.3 (individual cells) and $1 \mu \mathrm{m}$ (colonies). ii) For CCID collection, the Zeiss Axiovert 200 was used in conjunction with the AOBS Ultraview FRET H rapid confocal imaging system (Perkin Elmer Instruments Ltd., Beaconsfield, Buckinghamshire, England) with $z$-series imaging at $1-\mu \mathrm{m}$ intervals. Band-pass filter sets were used for respective fluorophore detection (excitation/filter/emission): eCFP (440 nm/CFP_Cy5/450 to 470 and 660 to $750 \mathrm{~nm}$ ); eGFP (488 $\mathrm{nm} / \mathrm{GFP} / 495$ to $562 \mathrm{~nm})$; eYFP $(514 \mathrm{~nm} / \mathrm{YFP} / 520$ to $650 \mathrm{~nm})$, dsRFP (568 nm/DAPI_mRFP/412 to $480 \mathrm{~nm}$ and 660 to $\geq 750$ $\mathrm{nm}$ ); and plant autofluorescence (440 nm/DAPI_mRFP/412 to $480 \mathrm{~nm}$ and 660 to $\geq 750 \mathrm{~nm}$ ). For consistency, all CCID were obtained at $10 \times$, using identical confocal parameters between infiltration variables.

\section{CCID.}

CCID was used as a means of quantifying confocal observations to allow objective and statistical comparison between infiltration variables. Three randomly selected $5-\mathrm{mm}^{2}$ sections of Pseudomonas syringae pv. phaseolicola eYFP-infiltrated tissue from the same leaf were examined at $10 \times$ (objective magnification), using the Zeiss confocal as above. random areas were imaged 12 times $(50 \times \mathrm{z}$-sections at $1-\mu \mathrm{m}$ intervals) from each leaf section and were combined (extended depth of field view) to represent a two-dimensional confocal image of all fluorescent Pseudomonas syringae pv. phaseolicola cells from each focal plane through the leaf mesophyll. Using ImageJ software (Abramoff et al. 2004), threshold algorithms converted confocal images into pixels and assigned eYFP emission pixels as white and non-eYFP emission pixels (plant material) as black (Fig. 2A to C). Quantification of pixel data enabled calculation of the percentage of white pixels (eYFP), which was expressed as the percent eYFP colony formation area within the mesophyll. The CCID percentage data presented was analyzed using a single factor analysis of variance test $(P<0.05)$ and standard error of the mean, using JMP IN 7.0 analysis software.

\section{Pseudomonas syringae pv. phaseolicola \\ bacterial growth rate determined from plant tissue extract.}

To compare CCID with viable eYFP-expressing bacterial cells present, a 5-mm diameter cork borer was used to extract infiltrated tissue adjacent to tissue samples analyzed by confocal imaging. Samples were pestle-ground in $500 \mu \mathrm{l}$ of onequarter Ringers solution, and serial dilutions were placed onto $\mathrm{KB}$ agar supplemented with $\mathrm{CHX}$ (to prevent fungal contamination) and NF (to select for Pseudomonas syringae pv. phaseolicola). Dilutions were also placed on KB agar supplemented with $\mathrm{CHX}, \mathrm{NF}$, and $\mathrm{Gm}$ (select for Tn7 eYFP inserts). All colonies were observed for correct colony morphology (compared with Pseudomonas syringae pv. phaseolicola 1302A and strain RJ3), and random colonies were pod-stab assayed to ensure correct $P$. vulgaris disease and HR phenotypes. Furthermore, all gentamicin-resistant colonies were assessed for eYFP expression using fluorescent stereo microscopy. Quantification of total colonies and gentamicin-resistant colonies provided percent eYFP survival.

\section{ACKNOWLEDGMENTS}

We thank L. Lambertsen and S. Molin for kindly supplying Tn7 fluorescent constructs. We also acknowledge M. Silby and J.-A. Gutierrez Barranquero for helpful contributions to this manuscript. This research was funded by a Biotechnology and Biological Sciences Research Council of the United Kingdom grant (BB/E001998/1). This work was carried out under FERA license number 217A/6185.

\section{LITERATURE CITED}

Abramovitch, R. B., Anderson, J. C., and Martin, G. B. 2006. Bacterial elicitation and evasion of plant innate immunity. Nat. Rev. Mol. Cell Biol. 7:601-611.

Alfano, J. R., and Collmer, A. 2004. Type III secretion system effector proteins: Double agents in bacteria disease. Annu. Rev. Phytopathol. 42:385-414.

Arnold, D. L., Jackson, R. W., Waterfield, N. R., and Mansfield, J. W. 2007. Evolution of microbial virulence: The benefits of stress. Trends Genet. 23:293-300

Badel, J. L., Charkowski, A. O., Deng, W. L., and Collmer, A. 2002. A gene in the Pseudomonas syringae pv. tomato Hrp pathogenicity island conserved effector locus, hopPtoAl, contributes to efficient formation of bacterial colonies in planta and is duplicated elsewhere in the genome. Mol. Plant-Microbe Interact. 15:1014-1024.

Bao, Y., Lies, D. P., Fu, H., and Roberts, G. P. 1991. An improved Tn7based system for the single-copy insertion of cloned genes into chromosomes of gram-negative bacteria. Gene. 109:167-168.

Beier, D., and Gross, R. 2006. Regulation of bacterial virulence by twocomponent systems. Curr. Opin. Microbiol. 9:143-152.

Bennett, M., Gallagher, M., Fagg, J., Bestwick, C., Paul, T., Beale, M., and Mansfield, J. 1996. The hypersensitive reaction, membrane damage and accumulation of autofluorescent phenolics in lettuce cells challenged by Bremia lactucae. Plant J. 9:851-865.

Bloemberg, G. V., Wijfjes, A. H. M., Lamers, G. E. M., Stuurman, N., and Lugtenberg, B. J. J. 2000. Simultaneous imaging of Pseudomonas fluorescens WCS365 populations expressing three different autofluorescent proteins in the rhizosphere: New perspectives for studying microbial communities. Mol. Plant-Microbe Interact. 13:1170-1176.

Chapman, S., Oparka, K. J., and Roberts, A. G. 2005. New tools for in vivo fluorescence tagging. Curr. Opin. Plant Biol. 8:565-573.

Compant, S., Reiter, B., Sessitsch, A., Nowak, J., Clement, C., and Ait Barka, E. 2005. Endophytic Colonization of Vitis vinifera L. by plant growth-promoting bacterium Burkholderia sp. strain PsJN. Appl. Environ. Microbiol. 71:1685-1693.

Danhorn, T., and Fuqua, C. 2007. Biofilm Formation by plant-associated bacteria. Ann. Rev. Microbiol. 61:401-422.

Davis, S. J., Vener, A. V., and Vierstra, R. D. 1999. Bacteriophytochromes: Phytochrome-like photoreceptors from nonphotosynthetic eubacteria Science. 286:2517-2520.

Dobrindt, U., Hochhut, B., Hentschel, U., and Hacker, J. 2004. Genomic islands in pathogenic and environmental microorganisms. Nat. Rev. Microbiol. 2:414-424.

Dulla, G., and Lindow, S. E. 2008. Quorum size of Pseudomonas syringae is small and dictated by water availability on the leaf surface. Proc. Natl. Acad. Sci. U.S.A. 105:3082-3087.

Elbeltagy, A., Nishioka, K., Sato, T., Suzuki, H., Ye, B., Hamada, T., Isawa, T., Mitsui, H., and Minamisawa, K. 2001. Endophytic colonization and in planta nitrogen fixation by a Herbaspirillum sp. isolated from wild rice species. Appl. Environ. Microbiol. 67:5285-5293.

Felix, G., Duran, J. D., Volko, S., and Boller, T. 1999. Plants have a sensitive perception system for the most conserved domain of bacterial flagellin. Plant J. 18:265-276.

Figurski, D. H., and Helinski, D. R. 1979. Replication of an origin-containing derivative of Plasmid RK2 Dependent on a plasmid function provided in Trans. Proc. Natl. Acad. Sci. U.S.A. 76:1648-1652.

Gal-Mor, O., and Finlay, B. B. 2006. Pathogenicity islands: A molecular toolbox for bacterial virulence. Cell. Microbiol. 8:1707-1719.

Gringauz, E., Orle, K. A., Waddell, C. S., and Craig, N. L. 1988. Recognition of Escherichia coli att Tn7 by transposon Tn7: Lack of specific sequence requirements at the point of $\operatorname{Tn} 7$ insertion. J. Bacteriol. 170:2832-2840. 
Hacker, J., and Kaper, J. B. 2000. Pathogenicity islands and the evolution of microbes. Ann. Rev. Microbiol. 54:641-679.

Han, S.-W., Park, C.-J., Lee, S.-W., and Ronald, P. 2008. An efficient method for visualization and growth of fluorescent Xanthomonas oryzae pv. oryzae in planta. BMC Microbiol. 8:164.

Hsiao, W. W. L., Ung, K., Aeschliman, D., Bryan, J., Finlay, B. B., and Brinkman, F. S. L. 2005. Evidence of a large novel gene pool associated with prokaryotic genomic islands. PLoS Genet. 1:e62. Published online.

Jackson, R. W., Mansfield, J. W., Arnold, D. A., Sesma, A., Paynter, C. D., Murillo, J., Taylor, J. D., and Vivian, A. 2000. Excision from tRNA genes of a large chromosomal region, carrying $a v r P p h B$, associated with race change in the bean pathogen, Pseudomonas syringae pv. phaseolicola. Mol. Microbiol. 38:186-197.

Jambunathan, N., Siani, J. M., and McNellis, T. W. 2001. A humidity-sensitive Arabidopsis copine mutant exhibits precocious cell death and increased disease resistance. Plant Cell. 13:2225-2240.

Jenner, C., Hitchin, E., Mansfield, J., Walters, K., and Betteridge, P. 1991. Gene-for-gene interactions between Pseudomonas syringae pv. phaseolicola and Phaseolus. Mol. Plant-Microbe Interact. 4:553-562.

Jones, J. D. G., and Dangl, J. L. 2006. The plant immune system. Nature. 444:323-329.

Kamoun, S., Huitema, E., and Vleeshouwers, V. G. A. A. 1999, Resistance to oomycetes: A general role for the hypersensitive response? Trends Plant Sci. 4:196-200.

King, E. O., Ward, M. K., and Raney, D. E. 1954. Two simple media for the demonstration of pyocyanin and fluorescen. J. Lab.Clin. Med. 44:301307.

Kombrink, E., and Schmelzer, E. 2001. The hypersensitive response and its role in local and systemic disease resistance. Eur. J. Plant Pathol. 107:69-78.

Kunze, G., Zipfel, C., Robatzek, S., Niehaus, K., Boller, T., and Felix, G. 2004. The $\mathrm{N}$ terminus of bacterial elongation factor $\mathrm{Tu}$ elicits innate immunity in Arabidopsis plants. Plant Cell. 16:3496-3507.

Lam, E. 2004. Controlled cell death, plant survival and development. Nat. Rev. Mol. Cell Biol. 5:305-315.

Lambertsen, L., Sternberg, C., and Molin, S. 2004. Mini-Tn7 transposons for site-specific tagging of bacteria with fluorescent proteins. Environ. Microbiol. 6:726-732.

Lindeberg, M., Stavrinides, J., Chang, J. H., Alfano, J. R., Collmer, A. Dangl, J. L., Greenberg, J. T., Mansfield, J. W., and Guttman, D. S. 2005. Unified nomenclature and phylogenetic analysis of extracellular proteins delivered by the type III secretion system of the plant pathogenic bacterium Pseudomonas syringae. Mol. Plant-Microbe Interact. $18: 275-282$

Lovell, H. C., Mansfield, J. W., Godfrey, S. A. C., Jackson, R. W., Hancock, J. T., and Arnold, D. L. 2009. Bacterial evolution by genomic island transfer occurs via DNA transformation in planta. Curr. Biol. 19:15861590 .

Mansfield, J. W., Jenner, C., Hockenhull, R., Bennett, M. A., and Stewart, R. 1994. Characterisation of avrPphE, a gene for cultivar-specific avirulence from Pseudomonas syringae pv. phaseolicola which is physically linked to $\operatorname{hrpY}$, a new hrp gene identified in the halo blight bacterium. Mol. Plant-Microbe Interact. 7:726-739.
Mattick, J. S. 2002. Type IV Pili and twitching motility. Ann. Rev. Microbiol. 56:289-314.

Nohmi, T. 2006. Environmental stress and lesion-bypass DNA polymerases. Ann. Rev. Microbiol. 60:231-253.

Pitman, A. R., Jackson, R. W., Mansfield, J. W., Kaitell, V., Thwaites, R., and Arnold, D. L. 2005. Exposure to host resistance mechanisms drives evolution of bacterial virulence in plants. Curr. Biol. 15:2230-2235.

Rico, A., and Preston, G. M. 2008. Pseudomonas syringae pv. tomato DC3000 uses constitutive and apoplast-induced nutrient assimilation pathways to catabolize nutrients that are abundant in the tomato apoplast. Mol. Plant-Microbe Interact. 21:269-282.

Saggaua, P. 2006. New methods and uses for fast optical scanning. Curr Opin. Neurobiol. 16:543-550.

Sambrook, J., Fritsch, E. F., and Maniatis, T. 1989. Molecular Cloning: A Laboratory Manual. Cold Spring Harbor Laboratory Press, Cold Spring Harbor, NY, U.S.A

Sun, W., Dunning, F. M., Pfund, C., Weingarten, R., and Bent, A. F. 2006. Within-species flagellin polymorphism in Xanthomonas campestris pv. campestris and its impact on elicitation of Arabidopsis FLAGELLIN SENSING2-dependent defenses. Plant Cell 18:764-779.

Taylor, J. D., Teverson, D. M., Allen, D. J., and Pastor-Corrales, M. A. 1996. Identification and origin of races of Pseudomonas syringae pv. phaseolicola from Africa and other bean growing areas. Plant Pathol. 45:469-478.

Threllfall, E. J., Rowe, B., Ferguson, J. L., and Ward, L. R. 1986. Characterisation of plasmids conferring resistance to gentamycin and apramycin in strains of Salmoella typhimurium phage type 204c isolated in Britain. J. Hyg. Camb. 97:419-426.

Vogler, A. P., Trentmann, S., and Lengeler, J. W. 1989. Alternative route for biosynthesis of amino sugars in Escherichia coli $\mathrm{K}-12$ mutants by means of a catabolic isomerase. J. Bacteriol. 171:6586-6592.

Whalen, M. C., Innes, R. W., Bent, A. F., and Staskawicz, B. J. 1991. Identification of Pseudomonas syringae pathogens of Arabidopsis and a bacterial locus determining avirulence on both Arabidopsis and soybean. Plant Cell. 3:49-59.

Wright, C. A., and Beattie, G. A. 2004. Pseudomonas syringae pv. tomato cells encounter inhibitory levels of water stress during the hypersensitive response of Arabidopsis thaliana. Proc. Natl. Acad. Sci. U.S.A. 101:3269-3274.

Yu, I. C., Parker, J., and Bent, A. F. 1998. Gene-for-gene disease resistance without the hypersensitive response in Arabidopsis dnd1 mutant. Proc. Natl. Acad. Sci. U.S.A. 95:7819-7824.

Zeidler, D., Zahringer, U., Gerber, I., Dubery, I., Hartung, T., Bors, W. Hutzler, P., and Durner, J. 2004. Innate immunity in Arabidopsis thaliana: Lipopolysaccharides activate nitric oxide synthase (NOS) and induce defense genes. Proc. Natl. Acad. Sci. U.S.A. 101:15811-15816.

Zimmermann, T., Rietdorf, J., and Pepperkok, R. 2003. Spectral imaging and its applications in live cell microscopy. FEBS (Fed. Eur. Biochem. Soc.) Lett. 546:87-92.

\section{AUTHOR-RECOMMENDED INTERNET RESOURCE}

JMP website: www.jmpin.com 